\title{
Early Childhood Educators' Perceptions of Dyslexia and Ability to Identify Students At-Risk
}

\author{
Michelle Gonzalez ${ }^{1} \&$ Tammy B. H. Brown ${ }^{2}$ \\ ${ }^{1}$ Department of Special Education \& Counseling, William Paterson University, Wayne, New Jersey, USA \\ ${ }^{2}$ School of Education, Marywood University, Scranton, Pennsylvania, USA \\ Correspondence: Michelle Gonzalez, Department of Special Education \& Counseling, William Paterson \\ University, 1600 Valley Road, Wayne, New Jersey, 07470 USA. E-mail: gonzalezm77@wpunj.edu
}

Received: December 20, $2018 \quad$ Accepted: January 18, $2019 \quad$ Online Published: March 29, 2019
$\begin{aligned} & \text { doi:10.5539/jel.v8n3p1 URL: https://doi.org/10.5539/jel.v8n3p1 }\end{aligned}$

\begin{abstract}
This study primarily explored the perceptions of dyslexia held by early childhood educators teaching in Head Start centers. A secondary purpose was to investigate how early childhood educators in Head Start centers perceive the notion of risk for dyslexia and how they identify at-risk students in ways that are consist with the results of a research-based assessment instrument. A case study approach was used for this study of two Head Start centers, one in the state of New Jersey and one in the state of Pennsylvania. Two teachers in each center $(n=4)$ and a total of 19 preschoolers participated in the study. Data were gathered using semi-structured interviews, observations, a teacher rating scale, and the Preschool Early Literacy Indicator (PELI) assessment. Findings indicate that the Head Start teachers held the prevailing misconception that dyslexia is a visual processing disorder rather than a phonological processing disorder. The Head Start teachers did not view phonemic awareness as a key factor in identifying children at-risk for dyslexia. Participants had a high success rate in identifying students at-risk in the areas of alphabet knowledge and oral language, but not in phonemic awareness and vocabulary. The results suggest that the stereotypes of dyslexia are hard to dispel and that professional development for pre-service and in-service teachers in early literacy practices and dyslexia are needed.
\end{abstract}

Keywords: teacher perception, literacy, dyslexia, early childhood

\section{Introduction and Literature Review}

Dyslexia, a term once eschewed by educational professionals in the United States because of the confusing and often inaccurate notions produced by the word, has recently gained more attention with an increase of state legislation. Between January and March of 2018, 33 new legislative bills concerning dyslexia were introduced across the United States. Further, states with specific dyslexia related legislation has grown substantially over the past five years (2013-2015). In 2013, 22 states had dyslexia related laws and currently in 2018, 42 states have laws specifically geared towards dyslexia (International Dyslexia Association [IDA], 2018). Early laws concerning dyslexia were general and vague; however, recent mandates have improved where states now have code that specifically defines dyslexia and provides guidance in the identification and selection of research-based interventions (Youman \& Mather, 2018). This surge of dyslexia related mandates illustrates that educators and law makers value the importance of identifying students with this exceptionality and providing appropriate evidence-based interventions.

Beginning with the 2014-2015 school year, New Jersey mandated dyslexia screening in the primary grades, as well as dyslexia-related professional development for teachers ("NJ Legislation", 2015). Though more states are mandating dyslexia screening in the early grades, very few of the mandates require professional development of teachers (IDA, 2018). New Jersey is the only state that mandates annual professional development for teachers in grades $\mathrm{K}-3$ including those who are reading specialists and special education teachers. The recent New Jersey laws suggest the advent of an important trend with regard to early identification of students at-risk for literacy difficulties and the importance of educators to have a solid understanding of evidence-based interventions. Although the value of early identification of at-risk readers has long been known (Snow, Burns, \& Griffin, 1998; Stanovich, 1986), the trend potentially perpetuates the narrowing of the notion of what it means to be literate, and specifically what it means to be at risk for literacy difficulties. 
For more than one-hundred years, researchers world-wide have been interested in dyslexia and have developed many theories to explain the nature of this learning disorder (Snowling, 2009). Although, one universal dyslexia definition does not exist, a well-regarded definition is provided by the International Dyslexia Association ([IDA], 2002). The IDA (2002) defines dyslexia as:

Dyslexia is a specific learning disability that is neurobiological in origin. It is characterized by difficulties with accurate and/or fluent word recognition and by poor spelling and decoding abilities. These difficulties typically result from a deficit in the phonological component of language that is often unexpected in relation to other cognitive abilities and the provision of effective classroom instruction. Secondary consequences may include problems in reading comprehension and reduced reading experience that can impede growth of vocabulary and background knowledge.

Though there is not one definition of dyslexia, a strong research base supports that dyslexia is neurobiological in nature and rooted in language deficits where individuals show difficulty in phonological processing. Further, research indicates that the severe word learning difficulties those with dyslexia have are connected to the areas of the brain related to phonological and orthographic processing (Davis et al., 2011). This research contrasts with the very early theories that dyslexia is related to vision, hearing, or intellectual deficits, which is a no longer valid (Shaywitz, 2003; Snowling \& Hulme, 2012; Vellutino, 1981). The dyslexic reader and the garden variety poor reader are not the same. Unlike other reading difficulties that may be related to cognitive ability, dyslexia is a language processing difficulty that occurs in the absence of deficient intellectual functioning or cognitive processing difficulties (Das, 2009; Spear-Swerling, 2004; Stanovich, 1988) and typically refers to those individuals with the most severe word learning difficulties (Peterson \& Pennington, 2012).

The word learning difficulties (i.e., word recognition, spelling, decoding) stem from weaknesses in an individual's phonological processing. Phonemic awareness (PA) falls under the broad umbrella of phonological processing and students with dyslexia most often have weakness in PA. PA is the ability to hear and manipulate individual sounds (phonemes) in words. PA is closely related to early word reading. In order for readers to decode words and encode them again, as is the process of reading, they must be aware of and manipulate language sounds. This is, in essence, the ability to crack the code of the alphabetic system of print. The alternative to decoding and encoding employed by individuals who lack or have weaknesses in phonemic awareness skills is reading by seeing and remembering whole words, which is a slow, laborious, and frustrating way to make sense of print (Sawyer \& Fox, 1991), one that often results in reading that lacks fluency and automaticity. Automaticity is a critical component of fluent, efficient, and effective reading (LaBerge \& Samuels, 1974; Pikulski \& Chard, 2005; Rasinski \& Padak, 2013). According to Ehri $(1995 ; 1998)$, such memory reading appears to be complicated even further by the nature of how readers actually store words in memory for efficient retrieval at sight (which is the hallmark of mature reading). Ehri's research suggests that efficient retrieval is dependent on the reader's ability to analyze the orthographic structure of the word and see a correspondence between sound and symbol. Another possible effect of a phonological deficit is an over-reliance on context, which can result in misidentification of the word in print (Das, 2009). Both can impede comprehension. Training in both phonemic awareness (Shaywitz, 2003) and fluency have been shown to be effective (Rasinski \& Padak, 2013), and early intervention is preferable (Shaywitz, 2003).

Although few individuals are incapable of learning to read, at least at a functional level (Shaywitz, 2003), the earlier at-risk readers are identified and provided with research-based intervention, the less likely the individual is to have a reading problem that increases in complexity (Stanovich, 1986). The New Jersey legislation as well as other state legislation on dyslexia is based on the literature indicating that children benefit from early diagnosis of reading difficulties (i.e., word learning) and early research-based intervention. The New Jersey law requires that teachers receive professional development, so they are equipped to recognize the risk factors for dyslexia.

In addition, according to the New Jersey code, if a child exhibits any indicators of dyslexia, they must be screened prior to the start of the second semester of second grade. Screening differs from evaluation in that screening is the identification of risk factors whereas evaluation is "the process of gathering information to identify the factors contributing to a student's difficulty with learning to read and spell" (Sawyer \& Jones, 2009, p. 1). Though the warning signs differ with age and grade, some of the first warning signs in preschool and kindergarten indicated by research include:

- Trouble learning common nursery rhymes, such as "Jack and Jill"

- Difficulty learning (and remembering) the names of letters in the alphabet

- Seems unable to recognize letters in his/her own name

- Mispronounces familiar words; persistent "baby talk" 
- Doesn't recognize rhyming patterns like cat, bat, rat

- Inability to learn to associate letters with sounds

- Does not understand that words come apart

- A family history of reading and/or spelling difficulties (dyslexia often runs in families) (Shaywitz, 2003, p. 122).

Early detection of reading difficulties is not only possible, but also yields lifelong benefits for the young child. When a child who is at-risk for dyslexia is identified early and receives effective intervention, outcomes improve (Wanzek \& Vaughn, 2007).

Misperceptions about dyslexia are common, even among pre-service and in-service educators and their professors. Specifically, in research conducted by Wadlington and Wadlington (2005), the majority of the participants believed the main diagnosis criteria of dyslexia was word reversal. More recent, Ness and Southall (2010) found similar results where $73 \%$ of pre-service teachers surveyed thought letter reversals was the main factor in identifying a student with dyslexia with only $30 \%$ of participants stating that dyslexia is a reading disability. On the other hand, research conducted by Washburn et al. (2011) found that most pre-service and in-service teachers believed that dyslexia was a language based disorder where students have trouble with decoding and spelling, but thought that using color overlays or tinted lenses would be an appropriate intervention, which relates to the inaccurate idea that dyslexia is a visual processing disorder. Early childhood educators are on the frontlines in identifying at-risk students and facilitating early and appropriate intervention. Spear-Swerling, Brucker, and Alfano (2005) argue that better understanding of the self-perceptions of literacy teachers is important in both teacher preparation and professional development. Further, the literacy content knowledge a teacher possesses directly relates to students receiving effective reading instruction (Snow, Griffin, \& Burns, 2005).

Thus, it is essential to gather information regarding early childhood teachers' perceptions and knowledge regarding dyslexia. Early childhood teachers are the first educators that can successfully identify any early signs of dyslexia and then provide needed interventions. Therefore, these educators need to have knowledge of the warning signs of dyslexia and appropriate interventions. Gathering data at Head Start centers in Pennsylvania and New Jersey allowed us to gain insight regarding these teachers' perceptions of dyslexia and to determine if professional development and screening mandates regarding dyslexia influenced these perceptions.

\section{Purpose and Research Questions of the Study}

The purpose of this study was to explore the perceptions of dyslexia held by early childhood educators teaching in Head Start centers in an effort to improve professional development programs. The study was guided by the following questions:

1) How do early childhood educators teaching in Head Start centers in New Jersey and Pennsylvania perceive dyslexia?

- What are the primary influences on these perceptions?

- Do Head Start teachers in Pennsylvania (where public-school screening at the primary level has not been mandated) and New Jersey (where public-school screening at the primary level has been mandated) differ?

2) How do early childhood educators teaching at Head Start centers perceive the notion of risk for dyslexia and do they identify at-risk students in ways that are consistent with the results of a research-based assessment instrument?

\section{Methods}

\subsection{Context and Participants}

A case study approach was used for this study of two Head Start centers, one in New Jersey and one in Pennsylvania. One researcher teaches at a university in New Jersey and one in Pennsylvania. Head Start centers were selected due to the population served at these centers. Head Start centers traditionally support the comprehensive development of young children (0-5) from low income families. We were interested in working with a low-income population because of the long-standing achievement gap that exists in literacy readiness skills between this group and high-income students (Reardon \& Potrilla, 2016). Though there is no link between low income status and dyslexia, we felt that that the combined factors of a child being at-risk for dyslexia and coming from a low SES background could be especially problematic for a child. Thus, we felt it was especially pertinent to collect the perceptions of dyslexia held by preschool teachers working in Head Start centers. 
The New Jersey Head Start center was located in a small city in the New York metropolitan area and the Pennsylvania Head Start center was located in a rural area. Two Head Start teachers participated in each center $(n$ =4). Several teachers at each site volunteered and site administrators were asked to select two for the study. First year teachers were excluded, as were teachers who were currently participating in other studies. Teachers instructing students who would be entering kindergarten in the upcoming school year were only selected. Each participant was given a pseudo name to ensure anonymity. A brief description of each teacher participant is below.

Amy is a teacher in the New Jersey Head Start center and in her early thirties. Originally from Scandinavia, she has a Bachelor of Arts in English and Early Childhood Education. This is her second-year teaching at the center. Previously, she worked as a Prekindergarten teacher at a private school for two years and prior to that she substituted in Prekindergarten through fifth grade in Scandinavia.

Brittany also teaches in the New Jersey Head Start center and is in her mid-twenties. She has a Bachelor of Arts in English Writing and does not hold a degree in education. Brittany has been employed at the current center for two years, but has worked in day care centers for the past nine years.

Chris, a female teacher in her mid-thirties, has a Bachelor of Science in Elementary Education and an additional certification in Early Childhood Education. She has been employed by the Pennsylvania Head Start center for ten years and worked as a substitute teacher for five years prior to teaching at the Pennsylvania center.

Donna, a teacher in her mid-thirties, has a Bachelor of Science in Early Childhood and a Master of Science in Literacy. She has been teaching at the current Pennsylvania Head Start center for ten years.

In order to answer the second research question, student participants were recruited. Parental consent forms to participate in the dyslexia screenings were returned for nineteen children with thirteen children from the Pennsylvania center (Donna $n=8$; Chris $n=5$ ) and six from the New Jersey center (Amy $n=5$; Brittany $n=1$ ). Non-native English-speaking students were excluded from the screenings. In order for the children to participate, they needed to be entering Kindergarten in the subsequent school year and be a native speaker of English.

\subsection{Data Collection}

Data collection was conducted in three phases. In the first phase of the study semi-structured interviews were conducted with the teacher participants concerning their perceptions of dyslexia. In the interviews, the teacher participants were asked to define dyslexia, identify the primary influences on their understanding, describe an at-risk child, and discuss appropriate interventions. In the second phase, student participants were given an early literacy screening and progress monitoring assessment called the Preschool Early Literacy Indicators (PELI; Dynamic Measurement Group). PELI is a storybook embedded screening assessment that assesses important pre-literacy and language skills needed for kindergarten (alphabet knowledge, vocabulary, oral language, phonemic awareness, and listening comprehension). The purpose of the assessment is to help identify students who may be at-risk for literacy difficulties. The testing materials appropriate for four and five-year olds were utilized. The test is untimed and takes approximately 15 minutes to administer. Total composite score and individual skill score results were utilized in the data analysis.

During the second phase, literacy instruction was also observed by the researchers. Observations during large group and small group instruction were completed, as well as observations during center time. In addition, the teacher participants were asked to complete a rating scale for each child who we received parental consent and student assent from. On the rating scale, the teacher participants evaluated each child's knowledge in the following five subskills of literacy: alphabet knowledge; phonemic awareness; oral, language; and listening comprehension. A score of 1-2 indicated no real concern, a rating of 3 indicated some concern, and a score of 4 indicated great concern for each subskill of literacy. A total score between 5 and 20 for the rating scale was also calculated. Receiving a total rating score of 5-8 translated to no concern; 9-15 as some concern; and 16-20 as great concern. The subskills of the rating scale mirrored the skills measured by the PELI in order to allow for seamless data analysis. In the final phase of data collection, the teacher participants were presented with the assessment data and asked to respond to and interpret the results. For example, the teachers were asked which results surprised them and what they might do differently in the classroom due to the results.

\subsection{Data Analysis}

Analysis of the qualitative data took place in the following stages: 1) Description of the literacy learning context; 2) Description of the belief systems of the participants; and 3) Cross-case look at teachers' beliefs using discourse analysis (Gee, 2005). A descriptive data analysis approach was required for comparing the results of the teacher rating scale and the PELI screening data. First, the overall PELI composite score was compared to the overall score on the teacher rating scale for each student participant. The mid-year benchmark data for the PELI were utilized to 
determine if each student participant was meeting the benchmark, not meeting it, but not necessarily at-risk, or at-risk for literacy difficulties. For instance, if a teacher, gave an overall score of 18 (great concern) on the rating scale and then the PELI composite score placed the child in the at-risk for literacy difficulties then the teacher was given credit for accurately identifying that student as being at-risk. On the same note, if the teacher gave an overall score of 5 (no concern) on the rating scale and the PELI composite score placed the student at meeting the benchmark, the teacher was also then given credit for accurately identifying the student for not being at-risk for literacy difficulties. This comparison was completed for each student and the teacher was then given an overall degree of accuracy percentage. To further analyze the data, each area of literacy assessed was then individually compared. The same protocol was followed as for the composite score to determine the degree of accuracy of the teachers' ratings on each individual area of literacy.

In order to improve the validity of the results, we took the following steps. First, researcher journaling (Creswell, 1998) was used as a means of addressing potential researcher bias. Peer review (Creswell, 1998) was used as we each analyzed the data sets separately; then compared our notes, and subsequently discussed similarities and differences. Finally, the data set was compared with a colleague's analysis who was not involved in data collection.

\section{Results}

\subsection{Early Childhood Educators' Perceptions of Dyslexia}

During the first phase of data collection, the early childhood teacher participants were asked to discuss their perceptions about dyslexia. After analyzing the data, a common theme emerged. Most of the early childhood educators perceived dyslexia as a visual processing problem. In other words, the teacher participants perceived that children with dyslexia or at-risk for dyslexia reverse letters or words in reading and writing or have difficulty seeing print, which aligns with the most noted enduring misconception of dyslexia. Key statements from the interview highlight the participants' perceptions and misconceptions.

Brittany stated, "When children or adults or whoever see things from right to left...It is more difficult for them to learn how to read and to see things." Similarly, Donna said, dyslexia is "Reversing things, having trouble with order like when they're reading and stuff or writing name backwards." Along the same lines, Chris said that dyslexia is when children "See letters backwards or whole words backwards." On the other hand, Amy was the only teacher participant who viewed dyslexia as a language-based disability. She stated. "(dyslexia) comes in all forms ... symptoms differ from child to child ... I think it is all parts of language-understanding, speaking, writing, listening, comprehending." Overall, most of the participants did not perceive dyslexia as a phonological processing disorder, but rather a visual processing disorder with the exception of Amy. Though, Amy made the connection between language and dyslexia and she understood that all students are not the same who have a diagnosis of dyslexia, her definition was still vague and lacked the key point that dyslexia is phonological processing disorder.

\subsection{Influence of Perceptions}

We were also interested as to what the primary factors may be that influenced the teacher participants' perceptions and definitions of dyslexia. Specifically, we were interested to see if the participants had college training or professional development on the topic of dyslexia. As noted previously, the perceptions of Brittany, Chris, and Donna aligned with myth that dyslexia is a visual processing disorder. Both Chris and Brittany received no professional development or had no college course work that addressed the topic of dyslexia. Therefore, we inferred that these participant perceptions were not influenced by training, but perhaps by the typical beliefs of mainstream society concerning dyslexia. On the other hand, Donna noted that her teacher preparation programs in early childhood and literacy had the most influence on her perceptions, which is concerning being that Donna's main perception of dyslexia was that it is a visual processing disorder. This finding brings up important points about how dyslexia is addressed in teacher education programs and the knowledge of the teacher educators about dyslexia. Lastly, Amy had no professional development on dyslexia, but remarked that she took one special education class in college that "Touched upon a little bit of everything, so I never got into too much depth about dyslexia." Thus, it appears that Amy gained some knowledge about dyslexia, but it was not in-depth. Overall, the influence of the participants' perceptions about dyslexia were most likely influenced by mainstream societal beliefs and/or some brief college training.

\subsection{Signs, Causes, and Interventions for Students At-Risk for Dyslexia}

The participants were asked to identify what signs they would look for in children to determine if they were at-risk for dyslexia. It was no surprise that the participants' responses aligned with their definitions or perceptions of 
dyslexia. Specifically, Amy stated that she would "Look for delayed speech or for students that don't follow directions well", which aligns with her language-based definition of dyslexia. However, Amy then went on to state that she would look for students who write their names backwards, which aligns with the visual processing myth of dyslexia and at the same time conflicts with her definition that dyslexia is a language-based disorder. This conflicting information may allude towards Amy's weak knowledge base concerning dyslexia. Further, the at-risk signs that Chris and Donna noted align again with the most prevailing myth of dyslexia. Chris stated, she would look for students "Who consistently confuses the lower-case b and $d$ and $p$ and $q$ " and Donna articulated she would look for students "Always writing their name backwards."

These perceptions illustrate a misconception between what is developmentally acceptable and what may be a risk factor for dyslexia. Many four and five-year-old children write their name backwards and confuse similar looking letters such as $b, d, p$, and $q$ as they are developing concepts of print and the brain is learning the difference between left and right. Many children learn the left to right orientation in reading and writing between the ages of five and eight. In contrast to Donna's and Amy's perceptions of letter reversals and writing names backwards, Chris stated she would look for "A child who at five still doesn't know any letters maybe other than $O$ and X." Donna's perception aligns with one of the early signs of dyslexia, which is difficulty learning and remembering the names of the letters of the alphabet (Shaywitz, 2003). Though the teacher participants articulated the signs they would look for in children at-risk, Brittany, Donna, and Chris all insisted that preschool children were too young to be identified for at-risk for dyslexia. Looking at the results overall, the teacher participants had some difficulty articulating the signs that young children may exhibit if they are at-risk for dyslexia.

In addition, the teacher participants discussed what they perceived as the cause of dyslexia. As noted in the literature, dyslexia is a neurobiological disability with a substantial genetic component (Powers et al., 2013). After analyzing the interview data, the themes that emerged were that dyslexia is caused by the way things are processed in the brain, by a genetic component, or is linked to environmental factors. For example, Chris felt that dyslexia is caused by the lack of exposure to language and literacy at home, as well as genetics. She stated dyslexia is caused by, "Someone who doesn't get read to. Doesn't really get to see words in print and have someone to tell them what those words mean. Or doesn't have parents who talk about and try to get them to learn their letters. Dyslexia could probably have something to do with genetics as well." Amy on the other hand associated dyslexia as a neurobiological disorder. She stated that dyslexia is caused by "How the brain processes words and sounds and letters and not seeing the full picture or hearing the full sentence." Though Amy was accurate in identifying dyslexia as being neurobiological in nature, she had some misconceptions as to exactly how the brain was involved in children with dyslexia. Although she hinted at the phonological component (sounds), she was unclear when stating students would not be able to see or hear. Both Donna and Brittany had some difficulty articulating the causes of dyslexia. Donna stated, "I don't even know. Um... is there really a cause to dyslexia? I always thought it was like a birth type thing." Even though Donna had trouble articulating a response, she did make a connection to the genetic component of dyslexia. Brittany on the other hand was transparent in her dearth of knowledge concerning the causes of dyslexia, In the interview she stated, "Honestly, I do not know. I do not want to tell you something just to tell you something."

Next, themes emerged when the participants were asked what type of interventions were needed for children at-risk for dyslexia. Overall, the teacher participants used catch phrases or made suggestions that lacked specificity when making suggestions for interventions. The use of catch phrases and general ideas for interventions can be related to the participants' definitions and conceptualizations of dyslexia. For instance, Brittany stated, "I would then have to maybe come up with some activities to assist him in better support his learning and development in that area, but then again, I would have to do my research to what could help him or her." Because participants had difficulty articulating the definition and at-risk factors for dyslexia, it is logical that ideas for intervention most likely would not align with the literacy practices used to address these at-risk factors.

Though most participants suggested general ideas or used catch phrases when discussing intervention ideas for children at-risk for dyslexia, Amy and Donna suggested interventions using literacy related terms. Amy stated, $I$ would use a lot of language modeling. Maybe at choice time take those extra minutes and sit with that child with whatever he's playing and have a conversation. Amy's response ties back to her belief that dyslexia is a language-based disability and that working on language with a child one-one one may be helpful. Amy also noted that embedded intervention (during choice time while the child is playing) would be the best time for intervention. Further, Donna specifically related her intervention ideas back to literacy, but again like her definition of dyslexia, her suggestions were rooted in the misconceptions of dyslexia (i.e., letter reversals and text directionality). Specifically, Donna focused her interventions on both herself and the parents. Donna noted that she would make sure that she modeled for the student how to write his/her name and the correct directionality when reading and 
writing. Donna also thought that parents should take the same approach as she does in the classroom by showing their child where to start when writing and reading. However, Donna was unsure if parents would even work with their child on these skills. Nevertheless, Donna felt repetition was key and if a child repeatedly saw his/her name written correctly and the correct way to read text then the child would eventually get it.

Finally, all participants articulated that they would seek the assistance of outside sources, such as parents, doctors, center directors, or therapists if faced with a child showing signs of dyslexia. Specifically, Amy would seek advice from early learning specialists and speech therapists, while Brittany stated she would seek help from the center director and the family advocate. Brittany felt that the family advocate would then seek help from doctors and therapists. Donna on the other hand would work with parents and viewed herself as a source in assisting the child. Chris focused on the assistance of the pediatrician and thought it would be useful if the pediatrician did not necessarily "Take the parents' word for what the child can and can't do" when questioned during well visits. Instead, Chris suggested that during annual well visits that the pediatrician should show the child letters to confirm if the child was at-risk.

\subsection{Early Childhood Educators' Identification of At-Risk Students in Comparison to a Research-Based Assessment Instrument}

After the initial interviews, data were collected from both the early childhood teacher participants and the student participants to determine how the teachers identify at-risk students in ways that are consistent with the results of a research-based assessment instrument. Using a researcher created rating scale, the teachers rated each student participant on alphabet knowledge, phonemic awareness, oral, language, and listening comprehension, which were the same skills assessed on the PELI, a research-based assessment instrument. Total scores and individual skill area scores on the PELI and rating scale were used in the comparison. In some instances, the teacher participants circled two numbers on the rating scale (i.e., 2 and 3 rather than just 2 or 3). When this occurred, the average score (i.e., 2.5) was used in the analysis. Results can be found in Table 1.

Table 1. Early childhood educators' rating accuracy

\begin{tabular}{lllllll}
\hline & $\begin{array}{l}\text { Alphabet } \\
\text { Knowledge }\end{array}$ & $\begin{array}{l}\text { Phonemic } \\
\text { Awareness }\end{array}$ & Vocabulary & Oral Language & $\begin{array}{l}\text { Listening } \\
\text { Comprehension }\end{array}$ & $\begin{array}{l}\text { Total Score } \\
\text { Ratings }\end{array}$ \\
\hline Amy $(n=5)$ & $100 \%$ & $60 \%$ & $40 \%$ & $100 \%$ & $60 \%$ & $0 \%$ \\
Brittany $(n=1)$ & $100 \%$ & $100 \%$ & $100 \%$ & $100 \%$ & $100 \%$ & $100 \%$ \\
NJ Overall & $100 \%$ & $80 \%$ & $70 \%$ & $100 \%$ & $80 \%$ & $50 \%$ \\
Chris $(n=5)$ & $80 \%$ & $60 \%$ & $20 \%$ & $40 \%$ & $60 \%$ & $20 \%$ \\
Donna $(n=8)$ & $100 \%$ & $25 \%$ & $50 \%$ & $87.5 \%$ & $75 \%$ & $12.5 \%$ \\
PA Overall & $90 \%$ & $42.5 \%$ & $35 \%$ & $63.75 \%$ & $67.5 \%$ & $16.25 \%$ \\
Overall Total & $95 \%$ & $61.25 \%$ & $52.5 \%$ & $81.88 \%$ & $73.75 \%$ & $33.13 \%$ \\
\hline
\end{tabular}

When comparing the overall rating scores and the composite scores of the PELI, the teacher participants had a low success rate $(33.13 \%)$ with predicting or identifying students who were either at-risk or had no risk factors for literacy difficulties. The exception was with Brittany. However, Brittany only had one student to rate rather than the multiple students the other participants rated, which may have impacted the overall accuracy. Thus, results indicate that the Head Start teachers had difficulty identifying at-risk students and students with no risk when using the total rating scale scores and the PELI composite scores.

The percent accuracy of the teachers was then examined by each individual literacy area assessed. Overall, teachers were most accurate in identifying students at-risk or having no risk in the area of alphabet knowledge (95\%). Three of the four teachers were able to identify at-risk students and students without risk with $100 \%$ accuracy. This was not surprising due to classroom observations during literacy instruction and centers where the focus was primarily on alphabet knowledge. Oral language was the other area of literacy where the teachers had the most success in identifying at risk students and students without risk with an overall $81.88 \%$ rate of success. Results indicate that the Head Start Teachers had a good sense of how students were performing in the area of alphabet knowledge and oral language. On the other hand, phonemic awareness $(61.25 \%)$ and vocabulary $(52.5 \%)$ were the literacy areas that the teachers had the most difficulty identifying students at risk or with little risk. When comparing the results of the New Jersey and Pennsylvania teachers, the New Jersey teachers outperformed the Pennsylvania teachers in all literacy areas, as well as in the total composite score. However, these results should be viewed with caution due to the uneven number of student participants that the Pennsylvania and New Jersey teachers evaluated, which can skew the interpretation of the results. 


\subsection{Teacher Interpretation of PELI Results}

After the administration and scoring of the assessments, the results were shared with the teacher participants. The teachers were asked if any results surprised them and what they would do differently in instruction to address any of the areas of need. Overall, the early educators noted that they were not surprised by the results of PELI assessment. However, if the results of the PELI indicated an area of risk for students, the teachers primarily took a passive stance to explain why the students were not meeting the required benchmark score rather than a possible indicator for an at-risk factor. For instance, the teachers noted that the results may have been related to the unfamiliar testing situation and students were not sure what to do. Other comments included that the skill was not addressed in the curriculum yet and that the teachers were confident the students would be on track by the end of the school year. Other remarks and rationales focused on attentional and maturity issues and parental influences. Specifically, Donna noted, "I kind of expected these results for Anna. She's very babied at home." Brittany noted, "I am not concerned, I just think that comes with maturity. I do not think that she can't remember. I just think it is just hard for her sometimes to sit through the whole thing." Because of the participants taking a passive stance on the results of the PELI, most did not suggest that they would do anything differently in their teaching practice based on the results of the PELI with Amy being the only exception. For instance, when presented results on the listening comprehension subtest of the PELI, Amy stated "I think with story time, I will have the students make predictions. I will make little notes for myself to remember to ask important comprehension questions because I think they will all benefit from it because if four children cannot answer what the book is about, I think this is something that I can work on with the whole class." Here Amy specifically states how she will change her shared reading teaching in order to help students comprehend stories more effectively.

Finally, when discussing the phonemic awareness results of the PELI, confusion about the nature of phonemic awareness emerged. For instance, when questioned about the phonemic awareness results of one student, Amy stated, "We do practice letter sounds, but I am not sure if Susan did not understand at all what to do". Similarly, Chris noted, "I mean with phonemic awareness we're already doing like letter sounds and you know. We've been doing the letter B recently and what does B look like, what does B sound like? What words start with B, you know trying to get the kids to come up with words." Brittany and Donna on the other hand discussed skills that fell under the umbrella of phonological awareness, but did not discuss skills specific to phonemic awareness. Both Brittany and Donna similar to Amy and Chris showed confusion between alphabet knowledge and phonemic awareness. Again, when shown the phonemic awareness results for Hailey, Brittany stated, "She likes when we do anything with rhyming or syllables, so she is actually good at separating the parts (syllables) of the words. As far as the letter sounds, I know Hailey is not too strong in that because we are still working on letter identification." Donna stated, "I think we're working on the alphabet as much as we could but maybe not the phonological part. I think I need to spend a little more time on the word parts and different sounds." Based on the teacher participants' responses during the final interview, it can be concluded that they did not have a firm understanding of the concepts of phonological and phonemic awareness.

\section{Discussion}

The purposes of this case study were to explore the perceptions of dyslexia held by early childhood educators teaching in Head Start programs in New Jersey and Pennsylvania and to determine if these educators identify at-risk students in ways that are consistent with the results of a research-based assessment instrument. Results of the study suggest that despite teachers approaching literacy instruction from a theme-based, socio-constructivist perspective, their perceptions of dyslexia are rooted in a skill-based, singular construct of reading, suggesting a disconnect between their beliefs about literacy development and their understanding of dyslexia. Consistent with the findings of Wadlington and Wadlington's (2005) work with pre-service and in-service elementary educators and their professors, the early childhood educators in this study held misconceptions about risk factors for dyslexia, as well as the efficacy of interventions at the preschool level. Specifically, perceptions of risk for dyslexia were found to be rooted in prevailing notions of dyslexia as seeing letters backward, as well as rooted in the belief dyslexia stems from a knowledge deficit or family literacy practices that do not align with school expectations. Overall, no significant differences in perceptions were noted between the Pennsylvania and New Jersey teachers, suggesting that policy mandates impacting public schools may not greatly impact teachers at the preschool level.

We advocate that it is necessary for early childhood education teachers to understand the at-risk factors and characteristics of dyslexia because lack of knowledge and misconceptions about dyslexia most likely can lead to ineffective literacy intervention. In the current study, most of the teachers felt dyslexia was a visual processing disorder. Therefore, a teacher with the visual processing misconception most likely will focus on having students write their names and letters correctly rather than phonemic awareness skills. This leads to a recommendation that preschool teachers need strong professional development in the area of dyslexia. 
The current study provides evidence towards the notion that early childhood educators are not verse in the key information regarding dyslexia and hold common misconceptions about the disorder, but the findings also allude towards gaps in early childhood educators' literacy content knowledge. The literacy instruction of the Head Start teachers in the study primarily focused on alphabet knowledge and writing names and letters. Though this is important content to include in an early literacy curriculum, other aspects were missing such as a deep linguistic and language connection to literacy (i.e., phonological skills). It is expected that preschool teachers explicitly and systematically teach and support students in the development of phonological skills, which is later connected to effortless word recognition. The current study supports the findings of Washburn, Binks-Cantrell, and Joshi (2013) who concluded that pre-service and in-service teachers educating young children do not have a strong understanding about phonology, phonics, morphology and other basic language and linguistic concepts.

Gaps in the Head Start teachers' knowledge about early literacy practices also were evident through the participants' misconceptions regarding phonemic awareness. In general, the participants believed phonemic awareness was understanding beginning letter sounds or they confused it with easier tasks found under the phonological awareness umbrella (i.e., rhyming, syllable identification). Furthermore, phonemic awareness was the literacy area that the teachers in the study had the least success in identifying students at-risk or having no risk. Difficulties in identifying students at-risk in the area of phonemic awareness may be closely related to the fact that both centers did not directly teach this skill. Instead, literacy instruction was focused on alphabet study, writing names, and more general language components and not the phonological component that research suggests. The focus on alphabet knowledge and general language component may also be related to how accurate teachers were in predicting at-risk or having no risk in the areas of alphabet knowledge and oral language. These were the two highest areas of accuracy for the study participants. These findings could indicate some relationship between content emphasis in early literacy curriculum and a teacher's ability to accurately predict a student's risk status in those same areas.

Further, the Head Start teachers did not seem to view phonemic awareness as a key factor in identifying children at-risk for dyslexia. This view is inconsistent with the research that suggests phonemic awareness plays a key role. Problems with phonemic awareness is one of the first symptom for later reading difficulties (Wadlington \& Wadlington, 2005). The confusion regarding phonemic awareness is concerning, as well as the lack of knowledge regarding the connection between phonemic awareness and dyslexia. It is important that early childhood teachers have a solid understanding of phonemic awareness and how to promote it because this skill is one of the strongest single indicator of a child's future reading success (Adams, 1990). Overall, early childhood teachers may lack the knowledge to promote literacy and at the same time over estimate their knowledge about early literacy, thus preventing these educators from seeking professional development (Cunningham, Zibulsky, \& Callahan, 2009).

In addition to weaknesses in early literacy content knowledge, the participants showed some misunderstanding concerning the developmental milestones in the area of literacy. This misunderstanding was illustrated by the participants consistently noting that preschool students who reverse letters or write their name backwards would be warning signs of dyslexia. Not only does this highlight the participants' misconception about dyslexia, but it also shows that participants did not understand that letter and name reversals are common in young children who are just learning and making sense of a complex writing system or orthography (Adams, 1990).

In the current study, none of the participants had strong professional development in the area of dyslexia, yet these educators are working with children at a critical age for literacy learning. The absence of professional development also relates to the participants' misconceptions and minimal knowledge about dyslexia. Participants' misconceptions about dyslexia may further be the reason why early childhood educators do not pursue professional development or discuss the topic of dyslexia. Specifically, the term dyslexia may not be welcomed or encouraged in fear of misuse or as the promotion of a negative label (Elliott, 2005). In the current study, the participants felt that preschool children were too young to be identified at-risk for dyslexia, thus resulting in no real need to pursue professional development on the topic. Though, the participants in the study had limited professional development and education concerning dyslexia, the results indicate that the stereotypes of dyslexia are hard to dispel.

\section{Implications and Conclusion}

The results of the study can inform professional development and teacher education programs at the preschool level, and they also suggest the need for further study of a larger population of early childhood educators. Further evaluation of the content of teacher preparation programs is needed as well as the evaluation of texts used in teacher education programs (Washburn, Mulcahy, Joshi, \& Binks-Cantrel, 2016). We advocate that dyslexia be covered (i.e., early signs, characteristics, research-based interventions, etc.) in teacher education programs, 
including those preparing early childhood educators. Adding dyslexia related content to teacher education programs, may additionally help dispel dyslexia misconceptions of teacher educators themselves. Wadlington and Wadlington (2005) found that teacher educators were more knowledgeable than the pre-service teachers, but they still held some common misconceptions concerning dyslexia, which is disconcerting. Educating pre-service, in-service, and professors may eliminate the fear of the misuse of the term dyslexia and the negative connotations that the term may hold.

To help address limitations of the study (i.e., small sample size) and to further explore teachers' beliefs about dyslexia and literacy additional research is recommended. Specifically, we recommend that research on the perceptions and knowledge teachers hold about dyslexia be conducted that extends the population of early childhood educators to include educators teaching in grades PreK-3. This will allow researchers to specifically explore if government mandates that require professional development on dyslexia is impacting teachers' perceptions and knowledge about dyslexia. In addition, the study invites further exploration of the connection between the beliefs and practices of early childhood educators.

Results of this study suggest that gaps in knowledge and misperceptions about dyslexia persist among some early childhood educators, despite a long-standing and growing body of research about the impact of early identification of at-risk students and the effectiveness of early intervention. Though attention brought to the topic by government mandates may be impacting early childhood educators in public schools affected by the mandates, this study calls into question what impact, if any, such mandates have on those who work with the youngest and neediest children. Early childhood educators have the potential to make an invaluable impact on the literacy development of preschool children at-risk for dyslexia. For this reason, teacher educators and reading researchers have an obligation to ensure that early childhood educators have the skills and willingness to undertake this important task of promoting the literacy growth of children at-risk for dyslexia.

\section{References}

Adams, M. (1990). Beginning to read: Thinking and learning about print. Cambridge, MA: MIT Press

Creswell, J. W. (1998). Qualitative inquiry and research design: Choosing among five traditions. Thousand Oaks, CA, US: Sage Publications, Inc.

Cunningham, A. E., Zibulsky, J., \& Callahan, M. D. (2009). Starting small: Building preschool teacher knowledge that supports early literacy development. Reading and Writing: An Interdisciplinary Journal, 22(4), 487-510. https://doi.org/10.1007/s11145-009-9164-z

Das, J. P. (2009). Reading difficulties and dyslexia: An interpretation for teachers. Thousand Oaks, CA: Sage.

Davis, N., Barquero, L., Compton, D. L., Fuchs, L. S., Fuchs, D., Gore, J. C., \& Anderson, A. W. (2011). Functional correlates of children's responsiveness to intervention. Developmental Neuropsychology, 36(3), 288-301. https://doi.org/10.1080/87565641.2010.549875

Ehri, L. C. (1995). Phases of development in learning to read words by sight. Journal of Research in Reading, 18, 116-125. https://doi.org/10.1111/j.1467-9817.1995.tb00077.x

Ehri, L. C. (1998). Grapheme-phoneme knowledge is essential for learning to read words in English. In J. L. Metsala \& L. C. Ehri (Eds.), Word recognition in beginning literacy (pp. 3-40). Mahwah, NJ: Erlbaum.

Gee, J. P. (2005). An introduction to discourse analysis: Theory and method. New York City, New York: Psychology Press.

International Dyslexia Association. (2002). Definition of dyslexia. Retrieved from https://dyslexiaida.org/definition-of-dyslexia/

International Dyslexia Association. (2018). Dyslexia law status by state: March 2018 update. Retrieved from https://dyslexiaida.org/dyslexia-laws-status-by-state/

LaBerge. D., \& Samuels, S. (1974). Toward a theory of automatic information processing in reading. Cognitive Psychology, 6, 293-323. https://doi.org/10.1016/0010-0285(74)90015-2

New Jersey Legislation. (2015, March 26). Retrieved March 28, 2015, from http://decodingdyslexianj.org/nj-legislation

Ness, M. K., \& Southall, G. (2010). Preservice teachers' knowledge of and beliefs about dyslexia. Journal of Reading Education, 36(1), 36-43.

Peterson, R. L., \& Pennington, B. F. (2012). Developmental dyslexia. Lancet (London, England), 379(9830), 1997-2007. https://doi.org/10.1016/S0140-6736(12)60198-6 
Pikulski J. J., \& Chard, D. J. (2005). Fluency: The bridge between decoding and reading comprehension. The Reading Teacher, 58(6), 510-519. https://doi.org/10.1598/RT.58.6.2

Powers, N. R., Eicher, J. D., Butter, F., Kong, Y., Miller, L. L., Ring, S., Mann, M., \& Gruen, J. R. (2013). Alleles of a polymorphic ETV6 binding site in DCDC2 confer risk of reading and language impairment. American Journal of Human Genetics, 93(1), 19-28. https://doi.org/10.1016/j.ajhg.2013.05.008

Rasinski, T., \& Padak, N. (2013). From fluency to comprehension: Powerful instruction through authentic reading. NY: Guilford.

Reardon, S. F., \& Portilla, X. A. (2016). Recent trends in income, racial, and ethnic school readiness gaps at kindergarten entry. AERA Open, 2(3), 1-18. https://doi.org/10.1177/2332858416657343

Sawyer, D. J., \& Fox, B. J. (1991). Phonological awareness in reading: The evolution of current perspectives. NY: Springer-Verlag. https://doi.org/10.1007/978-1-4612-3010-6

Sawyer, D. J., \& Jones, K. M. (2009). Just the facts: Testing and evaluation. The International Dyslexia Association. Retrieved from https://dyslexiaida.org/testing-and-evaluation/

Shaywitz, S. (2003). Overcoming dyslexia: A new and complete science-based program for reading problems at any level. NY: Random House.

Snow, C. E., Griffin P., \& Burns, M. S. (Eds.) (2005). Knowledge to support the teaching of reading: Preparing teachers for a changing world. San Francisco, CA: Jossey-Bass.

Snowling, M. J., (2009). Changing concepts of dyslexia: Nature, treatment and co-morbidity. Journal of Child Psychology and Psychiatry, 48, 609-618. https://doi.org/10.1111/j.1469-7610.2009.02197.x

Snowling, M. J., \& Hulme, C. (2012). Research review: The nature and classification of reading disorders-A commentary on proposals for DSM-5. Journal of Child Psychiatry, 53, 593-607. https://doi.org/10.1111/j.1469-7610.2011.02495.x

Spear-Swerling, L. (2004). A road map for under-standing reading disability and other reading problems: Origins, intervention, and prevention. In R. B. Ruddell \& N. J. Unrau (Eds.), Theoretical models and processes of reading (Vol. 5, pp. 517-573). Newark, DE: International Reading Association.

Spear-Swerling, L., Brucker, P. O., \& Alfano, M. P. (2005). Teachers' literacy-related knowledge and self-perceptions in relation to preparation and experience. Annals of Dyslexia, 55(2), 266-296. https://doi.org/10.1007/s11881-005-0014-7

Stanovich, K. E. (1986). Matthew Effects in Reading: Some consequences of individual differences in the acquisition of literacy. Reading Research Quarterly, 21(4), 360-407. https://doi.org/10.1598/RRQ.21.4.1

Stanovich, K. E. (1988). Explaining the differences between dyslexic and the garden-variety poor reader: The Phonological Core-Variable Difference Model. Journal of Learning Disabilities, 21, 590-604. https://doi.org/10.1177/002221948802101003

Vellutino, F. R. (1981). Dyslexia: Theory and research. Cambridge, MA: MIT Press.

Wadlington, E. M., \& Wadlington, P. L. (2005). What educators really believe about dyslexia. Reading Improvement, 42(1), 16-33.

Wanzek, J., \& Vaughn, S. (2007). Research-based implications from extensive early reading interventions. School Psychology Review, 36(4), 541-561.

Washburn, E. K., Joshi, R. M., \& Binks-Cantrell, E. S. (2011). Teacher knowledge of basic language concepts and dyslexia. Dyslexia, 17, 165-183. https://doi.org/10.1002/dys.426

Washburn, E. K., Binks-Cantrell, E. S., \& Joshi, R. M. (2013). What do preservice teachers from the USA and the UK know about dyslexia? Dyslexia, 20(1), 1-18. https://doi.org/10.1002/dys.1459

Washburn, E. K., Mulcahy, C. A., Joshi, R. M., \& Binks-Cantrel, E. (2016). Teacher knowledge of dyslexia. Perspectives on Language and Literacy, 42(4), 10-13.

Youman, M., \& Mather, N. (2018). Dyslexia laws in the USA: A 2018 update. Perspectives on Language and Literacy, $\quad 41, \quad 37-41 . \quad$ Retrieved from https://www.dyslexicadvantage.org/wp-content/uploads/2017/09/2018-Youman-Mather.pdf 


\section{Copyrights}

Copyright for this article is retained by the author, with first publication rights granted to the journal.

This is an open-access article distributed under the terms and conditions of the Creative Commons Attribution license (http://creativecommons.org/licenses/by/4.0/). 